\title{
Expression of Beclin 1 and Bcl-2 in pancreatic neoplasms and its effect on pancreatic ductal adenocarcinoma prognosis
}

\author{
SHANSHAN SONG, BAOSHENG WANG, SHUAILIN GU, XIAOCHENG LI and SHAOLONG SUN \\ Department of Pancreas and Endocrine Surgery, Shengjing Hospital of China Medical University, \\ Shenyang, Liaoning 110004, P.R. China
}

Received November 12, 2015; Accepted April 13, 2017

DOI: $10.3892 / \mathrm{ol} .2017 .7218$

\begin{abstract}
Aberrant expression of Beclin 1 and B-cell lymphoma-2 (Bcl-2) has been identified in a variety of human tumors; however, little information is available for pancreatic neoplasms. The present study analyzed the expression of Beclin 1 and $\mathrm{Bcl}-2$ in pancreatic ductal adenocarcinoma (PDAC) and solid pseudopapillary neoplasm (SPN) of the pancreas, and evaluated their prognostic significance for PDAC. The present study included 117 PDAC, 43 SPN and 32 chronic pancreatitis (CP) cases. Levels of Beclin 1 and Bcl-2 expression were evaluated semiquantitatively by immunohistochemistry, and their correlation with the survival of patients with PDAC was determined. Beclin 1 was upregulated in 74 (63.2\%) PDAC, 26 (60.5\%) SPN, and 14 (43.8\%) CP cases. Bcl-2 was upregulated in 38 (32.5\%) PDAC, $11(25.6 \%)$ SPN and $24(75.0 \%)$ CP cases. High Beclin 1 and low Bcl-2 expression was significantly correlated with poor differentiation and distant metastasis in PDAC, and associated with the presence of nuclear pleomorphism in SPN and with advanced Tumor-Node-Metastasis stage in PDAC. Beclin 1 and Bcl-2 levels were inversely correlated in PDAC, whereas they were positively correlated in SPN. Low Beclin 1 and high Bcl-2 expression was associated with improved disease-free survival and overall survival (OS). However, the association of Beclin 1 with survival was not significant in the Cox analysis, whereas Bcl-2 expression was significantly correlated with OS in the multivariate analysis. In conclusion, Beclin 1 upregulation exacerbated the progression and aggressiveness of pancreatic neoplasms, and $\mathrm{Bcl}-2$ downregulated expression was an independently poor prognostic factor for PDAC.
\end{abstract}

Correspondence to: Professor Shaolong Sun, Department of Pancreas and Endocrine Surgery, Shengjing Hospital of China Medical University, 36 Sanhao Street, Heping, Shenyang, Liaoning 110004, P.R. China

E-mail: sj_sunsl@126.com

Key words: Beclin 1, B-cell lymphoma 2, pancreatic ductal adenocarcinoma, solid pseudopapillary neoplasm, immunohistochemistry

\section{Introduction}

Pancreatic cancer is a highly aggressive cancer, with a 5-year overall survival (OS) rate of $<1.0 \%$, and is one of the most frequent causes of cancer-associated mortality worldwide (1). The poor outcome for patients with pancreatic cancer is associated with its late diagnosis due to the paucity of symptoms, rapid tumor progression and unresponsiveness to chemotherapy or radiotherapy. These parameters result in low resectability rates following diagnosis, early recurrence subsequent to resection and an overall poor survival rate (2). Therefore, pancreatic cancer is the object of extensive study, to obtain an improved understanding of the development and progression of the disease, and to improve the survival and quality of life of patients.

In total, $>90 \%$ of pancreatic cancer cases arise from the ductal epithelium of the pancreas and are termed pancreatic ductal adenocarcinoma (PDAC). Extensive efforts have been made to identify potential biomarkers that may be used to develop anti-metastatic treatments and improve prognostic evaluation (3). Unlike PDACs, solid pseudopapillary neoplasms (SPNs) of the pancreas are distinctive tumors that exhibit a low malignancy potential and are associated with a favorable prognosis following resection (4).

Autophagy, which is known as type II programmed cell death, is an important pathway for the degradation and recycling of cellular components and the response to stress (5). At basal levels, autophagy controls cellular homeostasis by removing potential intrinsic toxic components and enables cells to perform structural remodeling, which serves an essential role in cellular differentiation, development and survival in response to starvation conditions $(6,7)$. The aberrant regulation of these mechanisms contributes to the pathogenesis of a variety of diseases, including cancer $(6,8)$.

The Beclin 1 gene was the first mammalian autophagy gene identified, and it is located on chromosome 17q21 (6). Beclin 1 has received special attention in studies investigating autophagy, as it is the first autophagy protein demonstrated to be a haploinsufficient tumor suppressor in cancer cell experiments $(9,10)$. However, studies associating Beclin 1 with the pathogenesis of human cancer are limited, and the correlation is controversial. Decreased expression of Beclin 1 has been detected in glioblastoma (11), hepatocellular carcinoma (12), esophageal cancer (13), non-small cell 
lung cancer (14), bladder urothelial tumors (15) and breast cancer (16), whilst increased expression of Beclin 1 has been identified in ovarian cancer (17), colorectal cancer (18) and gastric cancer (19).

The BCL2, apoptosis regulator (BCL2) gene, located on chromosome $18 \mathrm{q} 21$, is a member of the Bcl-2 family, which serves an important role in apoptosis suppression $(20,21)$. The anti-apoptotic function extends cell survival in normal and tumor cells by inhibiting different cell death mechanisms (22). Bcl-2 is involved in cellular morphogenesis and differentiation; it functions as an oncogenic and anti-death molecule by modulating various homeostatic, developmental and disease processes (23-25). Although overexpression of Bcl-2 confers a survival advantage to the cell that may lead to rapid and uncontrolled cellular proliferation, which characterizes the development of cancer, differences in the expression of $\mathrm{Bcl}-2$ in numerous types of human cancer have been identified, similar to that found for Beclin 1. Bcl-2 downregulation has been revealed in breast cancer and pancreatic cancer $(26,27)$, whereas increased expression of Bcl-2 upregulation has also been demonstrated $(16,28)$. The significance of Bcl-2 expression for cancer prognosis remains unclear.

Beclin 1 was originally identified in a yeast two hybrid screen as a Bcl-2 family-interacting protein that serves a pivotal role in the process of autophagy (29). The binding between Beclin 1 and Bcl-2 is regulated by a variety of proteins and compounds that enhance or inhibit the Bcl-2/Beclin 1 interaction to repress or activate autophagy, and serve important roles in the crosstalk between autophagy and apoptosis $(30,31)$. The cooperation between Beclin 1 and Bcl-2 may additionally affect tumorigenesis and progression.

Studies suggest that Beclin1 and Bcl-2 expression in tumor cells varies according to tumor and tissue type, which requires additional investigation (11-19,26-28). There is a study that assesses Beclin 1 and Bcl-2 expression levels in pancreatic tumors, their interactions, and the correlation between their expression and patient survival (32). The aim of the present study was to examine the expression of Beclin 1 and Bcl-2 by immunohistochemistry in pancreatic neoplasms, including PDACs, SPNs and chronic pancreatitis (CP) tissues as the controls for PDAC. The expression of Beclin 1 and Bcl-2 was evaluated in correlation with clinicopathological parameters and the survival of patients to assess their value as markers of tumor development and prognosis.

\section{Patients and methods}

Patients and tissue samples. Formalin-fixed and paraffin-embedded tissue samples from 117 patients with PDAC, 43 patients with SPN and 32 patients with CP were selected from the archived materials of the Department of Pathology of Shengjing Hospital of China Medical University (Shenyang, China). The PDAC group consisted of 70 men and 47 women, the age of which ranged between 37 and 77 years (mean age \pm standard deviation, 58.89 \pm 9.27 ). The SPN group consisted of 5 men and 38 women, the age of which ranged between 9 and 65 years (mean age \pm standard deviation, 32.77 13.72 ). Patients diagnosed with PDAC, SPN or CP underwent pancreaticoduodenectomy or distal pancreatectomy between January 2011 and May 2014. Sufficient clinical and survival information of the PDAC and SPN patients was available.

Patients without complete survival information or those who succumbed to surgical complications were excluded from the study. No patients had received any neoadjuvant chemotherapy or chemoradiotherapy prior to the surgical resection. All patients were followed up by interview in the clinic or by phone call. Data on chemotherapy following surgery, disease-free survival (DFS) time and OS time were collected for each patient. Cases with distant metastasis or R1 resection were excluded from DFS evaluation. The total period of follow-up was 18-57 months.

All samples were initially stained with Mayer's hematoxylin for $5 \mathrm{~min}$ and $2 \%$ eosin for $1 \mathrm{~min}$ at room temperature; two independent investigators evaluated each section to confirm the foci and the differentiation of PDAC microscopically, and the most representative section from each case was used for immunohistochemical staining.

The present study was approved by the Clinical Ethics Committee of Shengjing Hospital of China Medical University.

Immunohistochemistry. Immunohistochemical staining was performed using the biotin-free polymer detection system. The formalin-fixed, paraffin-embedded sections (4- $\mu \mathrm{m}$ thick) were deparaffinized and dehydrated via dimethylbenzene and a graded alcohol series, respectively.

Microwave antigen retrieval was achieved in sodium citrate buffer ( $\mathrm{pH}$ 6.0) for Beclin 1, and in Tris-EDTA buffer ( $\mathrm{pH} 9.0$ ) for $\mathrm{Bcl}-2$, each for $20 \mathrm{~min}$ at $100^{\circ} \mathrm{C}$. Endogenous peroxidase activity was blocked by incubation with $0.3 \%$ hydrogen peroxidase at $37^{\circ} \mathrm{C}$ for $15 \mathrm{~min}$. Sections were then incubated with primary mouse monoclonal antibodies against Beclin 1 (1:400; cat. no. ab114071; Abcam, Cambridge, UK) and rabbit monoclonal antibodies against Bcl-2 (1:350; cat. no. ab32124; Abcam) at $4^{\circ} \mathrm{C}$ overnight. A two-step immunohistochemical staining kit was used for expression analysis (cat. no. PV-9000; Zhongshan Jinqiao Biotechnology Co. Ltd., Beijing, China). Tissue sections were then incubated with a polymer auxiliary for $15 \mathrm{~min}$ at $37^{\circ} \mathrm{C}$ and a biotin-free polymeric horseradish peroxidase-linked antibody-conjugate agent from the kit for $25 \mathrm{~min}$ at $37^{\circ} \mathrm{C}$. Following incubation, the reaction product was detected using diaminobenzidine (ZLI-9018; Zhongshan Jinqiao Biotechnology Co. Ltd., Beijing, China). Finally, the sections were counterstained with Mayer's hematoxylin as aforementioned, dehydrated, and mounted.

The normal ductal epithelium in breast tissue obtained from Pathology Department of Shengjing Hospital of China Medical University and the lymphocytes in the pancreatic stroma of the included pancreatic samples were used as positive controls for Beclin 1 and $\mathrm{Bcl}-2$, respectively. The negative controls were obtained by replacing the primary antibodies with $0.01 \mathrm{~mol} / 1$ phosphate-buffered saline.

Images were captured with a light microscope and NIS-Elements F3.0 software (Nikon Corporation, Tokyo, Japan).

Evaluation of immunohistochemical staining. Immunohistochemical sections were independently evaluated by two investigators in a blinded manner. At least five fields at a magnification, $x 400$ were randomly chosen 
per section. Cytoplasmic or membranous staining for Beclin 1 and Bcl-2 was considered to represent a positive immunoreaction. Beclin 1 and $\mathrm{Bcl}-2$ expression levels were estimated semiquantitatively based on the combination of staining intensity and the percentage of positively stained cells (proportion score). The staining intensity was scored as follows: 0, negative; 1 , weak; 2, moderate; and 3, strong. According to the percentage of positively stained cells in whole foci, the staining extent was categorized into 5 grades as follows: 0 , negative; $1,0-25 \% ; 2,26-50 \% ; 3,51-75 \%$; and $4,76-100 \%$. The intensity score and proportion score were multiplied together for a final score. Final scores were as follows for Beclin 1 and Bcl-2: $<6$, low expression; and $\geq 6$, high expression.

Clinical outcome assessment. DFS was calculated from the date of surgery to the date of detection of local recurrence/distant metastasis or to the date of mortality due to PDAC. DFS was only calculated in patients with R0 resection (free resection margins). Patients with $\mathrm{R} 1$ resection (resection margins invaded) were considered to have failure at time zero. OS was defined as the time from the date of surgery to the date of mortality or to the date of last follow-up if patients remained alive. The DFS of patients with PDAC was acquired in 97 cases with R0 resection; the mean DFS was 10.9 months (median, 6.0 months; range, 0.8-32.7 months). The OS of patients with PDAC was acquired in 117 cases; the mean OS was 13.6 months (median, 10.4 months; range, 1.37-42.0 months). None of the patients with SPN exhibited local recurrence/distant metastasis or had succumbed by the date of last follow-up.

Statistical analysis. Statistical analysis was performed using SPSS v.18.0 software (SPSS, Inc., Chicago, IL, USA). Pearson's $\chi^{2}$ test and Fisher's exact test were used to evaluate the association between Beclin 1 and Bcl-2 expression and several clinicopathological variables, and the difference between the Beclin 1 and Bcl-2 expression in PDAC and CP cases. The correlation coefficients ( $\mathrm{r}$ and P-values) between Beclin 1 and Bcl-2 among PDAC, SPN and CP tissues were obtained using the Spearman's test. Survival curves of DFS and OS were analyzed by the Kaplan-Meier method and compared with the log-rank test. Multivariate analysis of prognostic factors was tested with the Cox proportional hazards model. $\mathrm{P}<0.05$ was considered to indicate a statistically significant difference.

\section{Results}

Beclin 1 expression in pancreatic neoplasms. Assessment of Beclin 1 expression in pancreatic tissues demonstrated positive staining in cancerous foci, SPN foci and normal epithelium in CP tissues, and in the cytoplasm of intralobular ductal epithelial cells, acinar cells and pancreatic islet cells (Fig. 1). Pancreatic islet cells stained positive for Beclin 1, and were used as the positive control for Beclin 1 immunostaining in subsequent experiments. High Beclin 1 expression was observed in 74 (63.2\%) PDAC cases, while 43 (36.8\%) PDAC cases demonstrated low expression. PDAC tissues exhibited significantly higher Beclin 1 expression compared with the normal ductal epithelium in CP tissues $(\mathrm{P}=0.047)$ (Table I).
The association between Beclin 1 expression and the clinicopathological characteristics of patients with PDAC is described in Table II. High Beclin 1 expression was correlated with poor histological differentiation $(\mathrm{P}=0.001)$ and distant metastasis $(\mathrm{P}=0.021)$.

High Beclin 1 expression was detected in $26(60.5 \%)$ patients with SPN and was correlated with pancreatic body or tail location $(\mathrm{P}=0.018)$ and the presence of nuclear pleomorphism $(\mathrm{P}=0.031)$. There was no significant correlation between Beclin 1 expression and other clinicopathological features (Table III).

Bcl-2 expression in pancreatic neoplasms. Cytoplasmic or membranous Bcl-2 immunostaining was observed in the majority of the normal ductal (intralobular and interlobular) cells and certain acinar compartments, whilst no staining was observed in the endocrine component (Fig. 2).

Decreased Bcl-2 expression was detected in PDAC foci compared with the normal ductal epithelium (Table I). High Bcl-2 expression was detected in 38 (32.5\%) PDAC cases, while $79(67.5 \%)$ PDAC cases demonstrated low expression. The correlation between $\mathrm{Bcl}-2$ and the clinicopathological characteristics of PDAC patients is summarized in Table II. Decreased Bcl-2 expression was correlated with cancerous pancreatic body or tail location ( $\mathrm{P}=0.017)$, poor histological differentiation $(\mathrm{P}=0.002)$, distant metastasis $(\mathrm{P}=0.049)$ and advanced Tumor-Node-Metastasis (TNM) (33) stage ( $\mathrm{P}=0.017)$.

High Bcl-2 expression was detected in 11 (25.6\%) patients with SPN. There was no significant correlation between Bcl-2 expression and clinicopathological features in SPN (Table III).

Association between Beclin 1 and Bcl-2 expression. As demonstrated in Table IV, Beclin 1 expression level was not associated with $\mathrm{Bcl}-2$ expression in $\mathrm{CP}$ cases $(\mathrm{P}=0.629$, $\mathrm{r}=0.073)$. However, there was a statistically significant inverse correlation $(\mathrm{P}<0.001, \mathrm{r}=-0.342)$ between the level of Beclin 1 and $\mathrm{Bcl}-2$ expression in PDAC cases. A statistically significant direct correlation $(\mathrm{P}=0.016, \mathrm{r}=0.365)$ was detected between Beclin 1 and Bcl-2 expression in SPN cases.

Association of clinicopathological characteristics, Beclin 1/Bcl-2 expression and patient survival in PDAC: A univariate survival analysis. Univariate survival analysis with the Kaplan-Meier method and log-rank test was used to calculate the effect of well-established clinical prognostic factors and the levels of Beclin 1 and Bcl-2 expression on the DFS and OS of patients with PDAC (Table V). The outcomes demonstrated that longer DFS was significantly correlated with head location $(\mathrm{P}=0.001)$, improved differentiation $(\mathrm{P}<0.001)$, limited tumor size and local invasion ( $\mathrm{T}$ stage; $\mathrm{P}=0.003)$ and high expression of $\mathrm{Bcl}-2(\mathrm{P}=0.030)$. The median DFS of patients with high Beclin 1 expression was shorter compared with that of patients with low expression, although the difference did not reach statistical significance (Fig. 3A).

The effects of prognostic factors on OS was next analyzed. The results demonstrated that a longer OS was significantly associated with pancreatic head location $(\mathrm{P}=0.004)$, improved differentiation $(\mathrm{P}<0.001)$, limited tumor size and local invasion $(\mathrm{P}<0.001)$, negative lymph node metastasis $(\mathrm{P}=0.022)$, no distant metastasis $(\mathrm{P}<0.001)$ and lower TNM stage $(\mathrm{P}<0.001)$. 
Table I. Expression of Beclin 1 and Bcl-2 in PDAC and CP tissues.

\begin{tabular}{|c|c|c|c|c|c|c|c|}
\hline \multirow[b]{2}{*}{ Tissue type } & \multirow[b]{2}{*}{ Cases, $\mathrm{n}$} & \multicolumn{2}{|c|}{ Beclin 1} & \multirow[b]{2}{*}{ P-value } & \multicolumn{2}{|c|}{$\mathrm{Bcl}-2$} & \multirow[b]{2}{*}{ P-value } \\
\hline & & Low, n (\%) & High, n (\%) & & Low, n (\%) & High, n (\%) & \\
\hline PDAC & 117 & $43(36.8)$ & $74(63.2)$ & $0.047^{\mathrm{a}}$ & 79 (67.5) & $38(32.5)$ & $<0.001^{\mathrm{a}}$ \\
\hline $\mathrm{CP}$ & 32 & $18(56.3)$ & $14(43.8)$ & & $8(25.0)$ & $24(75.0)$ & \\
\hline
\end{tabular}

${ }^{a}$ PDAC vs. CP, significantly differently by the $\chi^{2}$ test. Bcl-2, B-cell lymphoma-2; PDAC, pancreatic ductal adenocarcinoma; CP, chronic pancreatitis.
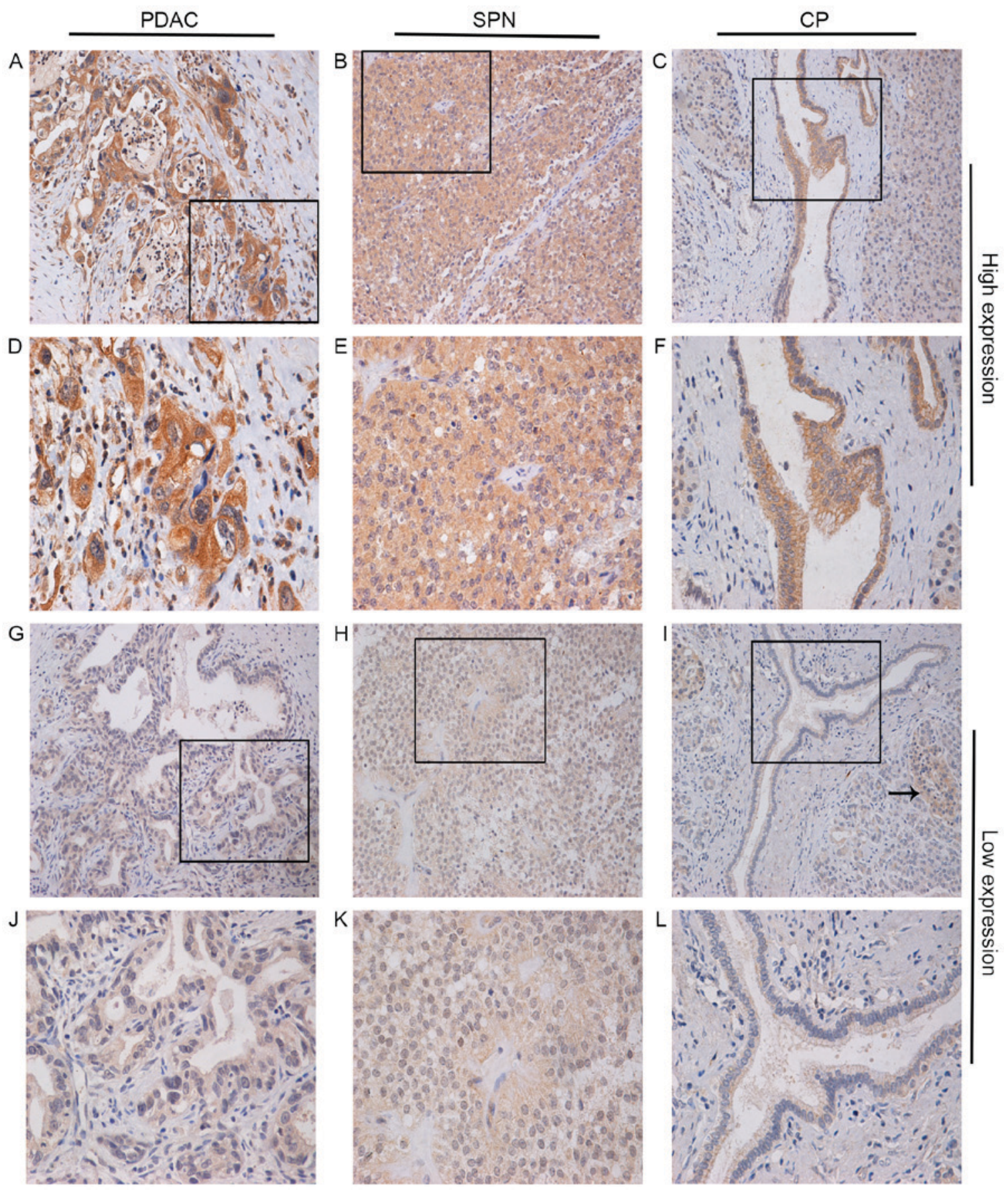

Figure 1. Immunohistochemical staining for high Beclin 1 expression in PDAC tissues at (A) magnification, $\mathrm{x} 200$ and (D) x400, in SPN tissues at (B) magnification, $\times 200$ and (E) x400, and in normal ductal epithelium in CP tissues at (C) magnification, $\times 200$ and (F) x400. Low Beclin 1 expression in PDAC tissues at (G) magnification, x200 and (J) x400, in SPN tissues at (H) magnification, x200 and (K) x400, and in normal ductal epithelium in CP tissues at (I) magnification, x200 and (L) x400. Pancreatic islet cells were positively stained with Beclin 1 in each sample (arrow). PDAC, pancreatic ductal adenocarcinoma; SPN, solid-pseudopapillary neoplasm; CP, chronic pancreatitis. 
Table II.Association of Beclin 1 and Bcl-2 expression with clinicopathological characteristics in pancreatic ductal adenocarcinoma.

\begin{tabular}{|c|c|c|c|c|c|c|c|}
\hline \multirow[b]{2}{*}{ Characteristics } & \multirow[b]{2}{*}{ Cases, $\mathrm{n}$} & \multicolumn{2}{|c|}{ Beclin 1} & \multirow[b]{2}{*}{ P-value } & \multicolumn{2}{|c|}{ Bcl-2 } & \multirow[b]{2}{*}{ P-value } \\
\hline & & Low, n (\%) & High, n (\%) & & Low, n (\%) & High, n (\%) & \\
\hline Age, years $($ mean $=58.98)$ & & & & 0.518 & & & 0.646 \\
\hline$<58.98$ & 59 & $20(33.9)$ & $39(66.1)$ & & $41(69.5)$ & $18(30.5)$ & \\
\hline$\geq 58.98$ & 58 & $23(39.7)$ & $35(60.3)$ & & $38(65.5)$ & $20(34.5)$ & \\
\hline Sex & & & & 0.064 & & & 0.485 \\
\hline Female & 47 & $22(46.8)$ & $25(53.2)$ & & $30(63.8)$ & $17(36.2)$ & \\
\hline Male & 70 & $21(30.0)$ & $49(70.0)$ & & $49(70.0)$ & $21(30.0)$ & \\
\hline Smoker & & & & 0.170 & & & 0.332 \\
\hline No & 75 & $31(41.3)$ & $44(58.7)$ & & $53(70.7)$ & $22(29.3)$ & \\
\hline Yes & 42 & $12(28.6)$ & $30(71.4)$ & & $26(61.9)$ & $16(38.1)$ & \\
\hline Diabetes & & & & 0.631 & & & 0.629 \\
\hline No & 104 & $39(37.5)$ & $65(62.5)$ & & $71(68.3)$ & $33(31.7)$ & \\
\hline Yes & 13 & $4(30.8)$ & $9(69.2)$ & & $8(61.5)$ & $5(38.5)$ & \\
\hline CA19-9, U/ml ${ }^{\mathrm{b}}$ & & & & 0.585 & & & 0.871 \\
\hline$\leq 37$ & 27 & $9(33.3)$ & $18(66.7)$ & & $18(66.7)$ & $9(33.3)$ & \\
\hline$>37$ & 79 & $31(39.2)$ & $48(60.8)$ & & $54(68.4)$ & 25 (31.6) & \\
\hline $\mathrm{CEA}, \mathrm{ng} / \mathrm{ml}^{\mathrm{b}}$ & & & & 0.915 & & & 0.996 \\
\hline$\leq 5$ & 78 & $29(37.2)$ & $49(62.8)$ & & $53(67.9)$ & $25(32.1)$ & \\
\hline$>5$ & 25 & $9(36.0)$ & $16(64.0)$ & & & & \\
\hline Location & & & & 0.235 & & & $0.017^{\mathrm{a}}$ \\
\hline Head & 85 & $34(40.0)$ & $51(60.0)$ & & $52(61.2)$ & $33(38.8)$ & \\
\hline Body/Tail & 32 & $9(28.1)$ & $23(71.9)$ & & $27(84.4)$ & $5(15.6)$ & \\
\hline Differentiation & & & & $0.001^{\mathrm{a}}$ & & & $0.002^{\mathrm{a}}$ \\
\hline Well & 21 & $12(57.1)$ & $9(42.9)$ & & $11(52.4)$ & $10(47.6)$ & \\
\hline Moderate & 71 & $29(40.8)$ & $42(59.2)$ & & $44(62.0)$ & $27(38.0)$ & \\
\hline Poor & 25 & $2(8.0)$ & $23(92.0)$ & & $24(96.0)$ & $1(4.0)$ & \\
\hline T stage & & & & 0.786 & & & 0.577 \\
\hline $\mathrm{T} 1 / \mathrm{T} 2$ & 39 & $15(38.5)$ & $24(61.5)$ & & $25(64.1)$ & $14(35.9)$ & \\
\hline T3/T4 & 78 & $28(35.9)$ & $50(64.1)$ & & $54(69.2)$ & $24(30.8)$ & \\
\hline $\mathrm{N}$ stage & & & & 0.390 & & & 0.351 \\
\hline N0 & 73 & $29(39.7)$ & $44(60.3)$ & & $47(64.4)$ & $26(35.6)$ & \\
\hline N1 & 44 & $14(31.8)$ & $30(68.2)$ & & $32(72.7)$ & $12(27.3)$ & \\
\hline M stage & & & & $0.021^{\mathrm{a}}$ & & & $0.049^{\mathrm{a}}$ \\
\hline M0 & 100 & $41(41.0)$ & $59(59.0)$ & & $64(64.0)$ & $36(36.0)$ & \\
\hline M1 & 17 & $2(11.8)$ & $15(88.2)$ & & $15(88.2)$ & $2(11.8)$ & \\
\hline TNM stage & & & & 0.235 & & & $0.017^{\mathrm{a}}$ \\
\hline $\mathrm{I} / \mathrm{II}$ & 85 & $34(40.0)$ & $51(60.0)$ & & $52(61.2)$ & $33(38.8)$ & \\
\hline III/IV & 32 & $9(28.1)$ & $23(71.9)$ & & $27(84.4)$ & 5 (15.6) & \\
\hline
\end{tabular}

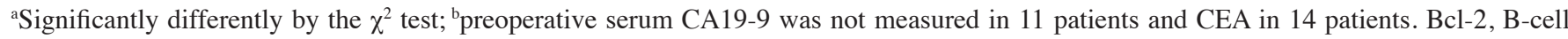
lymphoma-2; CA19-9, carbohydrate antigen 19-9; CEA, carcinoembryonic antigen; TNM, Tumor-Node-Metastasis.

Low expression of Beclin 1 and high expression of Bcl-2 were predictive factors of improved $\mathrm{OS}(\mathrm{P}=0.038$ and $\mathrm{P}=0.017$, respectively; Fig. 3C and D).

Independent prognostic factors of PDAC: A multivariate survival analysis. To avoid the bias of univariate analysis, the expression of Beclin 1, Bcl-2 and other characteristics were examined by multivariate Cox analysis (Table V). In the multivariate analysis, Beclin 1 and $\mathrm{Bcl}-2$ were not independent prognostic parameters for DFS [Beclin 1: Hazard ratio (HR), 0.870; 95\% confidence interval (CI), 0.532-1.423; $\mathrm{P}=0.580$; Bcl-2: HR, 1.400; 95\% CI, 0.810-2.421; $\mathrm{P}=0.228]$. DFS was affected by improved differentiation (HR, 0.399; 95\% CI, 0.190-0.839; $\mathrm{P}=0.015)$ and limited tumor size and 
Table III. Association of Beclin 1 and Bcl-2 expression with clinicopathological characteristics in solid-pseudopapillary neoplasms.

\begin{tabular}{|c|c|c|c|c|c|c|c|}
\hline \multirow[b]{2}{*}{ Characteristics } & \multirow[b]{2}{*}{ Cases, $\mathrm{n}$} & \multicolumn{2}{|c|}{ Beclin 1} & \multirow[b]{2}{*}{ P-value } & \multicolumn{2}{|c|}{ Bcl-2 } & \multirow[b]{2}{*}{ P-value } \\
\hline & & Low, n (\%) & High, n (\%) & & Low, n (\%) & High, n (\%) & \\
\hline Age, years $($ mean=32.77) & & & & 0.207 & & & 0.399 \\
\hline$<32.77$ & 28 & $13(46.4)$ & $15(53.6)$ & & $22(78.6)$ & $6(21.4)$ & \\
\hline$\geq 32.77$ & 15 & $4(26.7)$ & $11(73.3)$ & & $10(66.7)$ & $5(33.3)$ & \\
\hline Sex & & & & 0.633 & & & 0.096 \\
\hline Male & 5 & $1(20.0)$ & $4(80.0)$ & & $2(40.0)$ & $3(60.0)$ & \\
\hline Female & 38 & $16(42.1)$ & $22(57.9)$ & & $30(78.9)$ & $8(21.1)$ & \\
\hline Location & & & & $0.018^{\mathrm{a}}$ & & & 0.116 \\
\hline Head & 16 & $10(62.5)$ & $6(37.5)$ & & $14(87.5)$ & $2(12.5)$ & \\
\hline Body/Tail & 27 & $7(25.9)$ & $20(74.1)$ & & $18(66.7)$ & $9(33.3)$ & \\
\hline Size, cm & & & & 0.859 & & & 0.802 \\
\hline$<6.75$ & 26 & $10(38.5)$ & $16(61.5)$ & & $19(73.1)$ & $7(26.9)$ & \\
\hline$\geq 6.75$ & 17 & $7(41.2)$ & $10(58.8)$ & & $13(76.5)$ & $4(23.5)$ & \\
\hline Tumor feature & & & & 0.834 & & & 0.422 \\
\hline Solid & 16 & $6(37.5)$ & $10(62.5)$ & & $13(81.3)$ & $3(18.8)$ & \\
\hline Cystic and solid & 27 & $11(40.7)$ & $16(59.3)$ & & $19(70.4)$ & $8(29.6)$ & \\
\hline Nuclear pleomorphism, HPFs & & & & $0.031^{\mathrm{a}}$ & & & 0.273 \\
\hline$<10$ & 36 & $17(47.2)$ & $19(52.8)$ & & $28(77.8)$ & $8(22.2)$ & \\
\hline$\geq 10$ & 7 & $0(0.0)$ & $7(100.0)$ & & $4(57.1)$ & $3(42.9)$ & \\
\hline Peripancreatic invasion & & & & 0.446 & & & 0.967 \\
\hline Yes & 8 & $2(25.0)$ & $6(75.0)$ & & $6(75.0)$ & $2(25.0)$ & \\
\hline No & 35 & $15(42.9)$ & $20(57.1)$ & & $26(74.3)$ & $9(25.7)$ & \\
\hline Cytokeratin & & & & 0.749 & & & 1.000 \\
\hline+ & 21 & $8(38.1)$ & $13(61.9)$ & & $15(71.4)$ & $6(28.6)$ & \\
\hline- & 16 & 7 & 9 & & $11(68.8)$ & $5(31.3)$ & \\
\hline Synaptophysin & & & & 1.000 & & & 1.000 \\
\hline+ & 18 & $7(38.9)$ & $11(61.1)$ & & $12(66.7)$ & $6(33.3)$ & \\
\hline- & 13 & $5(38.5)$ & $8(61.5)$ & & $8(61.5)$ & $5(38.5)$ & \\
\hline
\end{tabular}

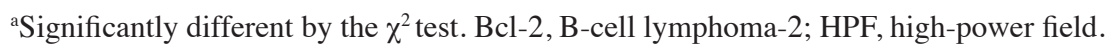

local invasion (HR, 0.399; 95\% CI, 0.190-0.839; $\mathrm{P}=0.014)$ independently.

Bcl-2 was an independent prognostic biomarker for OS (HR, 1.850; 95\% CI, 1.053-3.249; $\mathrm{P}=0.032)$, whereas Beclin 1 was not an independent prognostic parameter for OS (HR, 0.927; 95\% CI, 0.557-1.543; $\mathrm{P}=0.771$ ). No smoking (HR, 0.546; 95\% CI, 0.326-0.914; $\mathrm{P}=0.021)$, improved differentiation (HR, 0.394; 95\% CI, 0.201-0.774; $\mathrm{P}=0.007)$, limited tumor size and local invasion (HR, 0.307; 95\% CI, 0.175-0.539; $\mathrm{P}<0.001)$ and chemotherapy following surgery (HR, 2.415; 95\% CI, 1.218-4.544; $\mathrm{P}=0.006$ ) were also associated with improved $\mathrm{OS}$.

\section{Discussion}

The burden of pancreatic cancer is increasing worldwide, making it a serious health concern. Risk factors such as older age, smoking and long-term diabetes mellitus have been associated with pancreatic tumorigenesis (34). Surgical resection is considered the best potentially curative treatment; however, the majority of patients are diagnosed at an unresectable locally advanced or distal metastatic stage due to the aggressiveness of the disease (34). The effects of surgical resection on OS remains minimal, and the local failure rate is as high as $50-80 \%$ in patients who successfully undergo surgical resection, resulting in poor quality of life (35). Pancreatic cancer is difficult to prevent and diagnose early; it progresses rapidly and exhibits a poor prognosis. Therefore, extensive studies have been conducted to understand the mechanisms underlying pancreatic cancer development at the biochemical, genomic and proteomic levels to inhibit the progression of pancreatic cancer and to improve patient prognosis.

Autophagy and apoptosis have been studied extensively in association with tumor progression in previous years, particularly Beclin 1 and Bcl-2 as the primary factors in the 2 programmed cell death pathways. The correlation between autophagy and apoptosis is complex and varies with cell type 

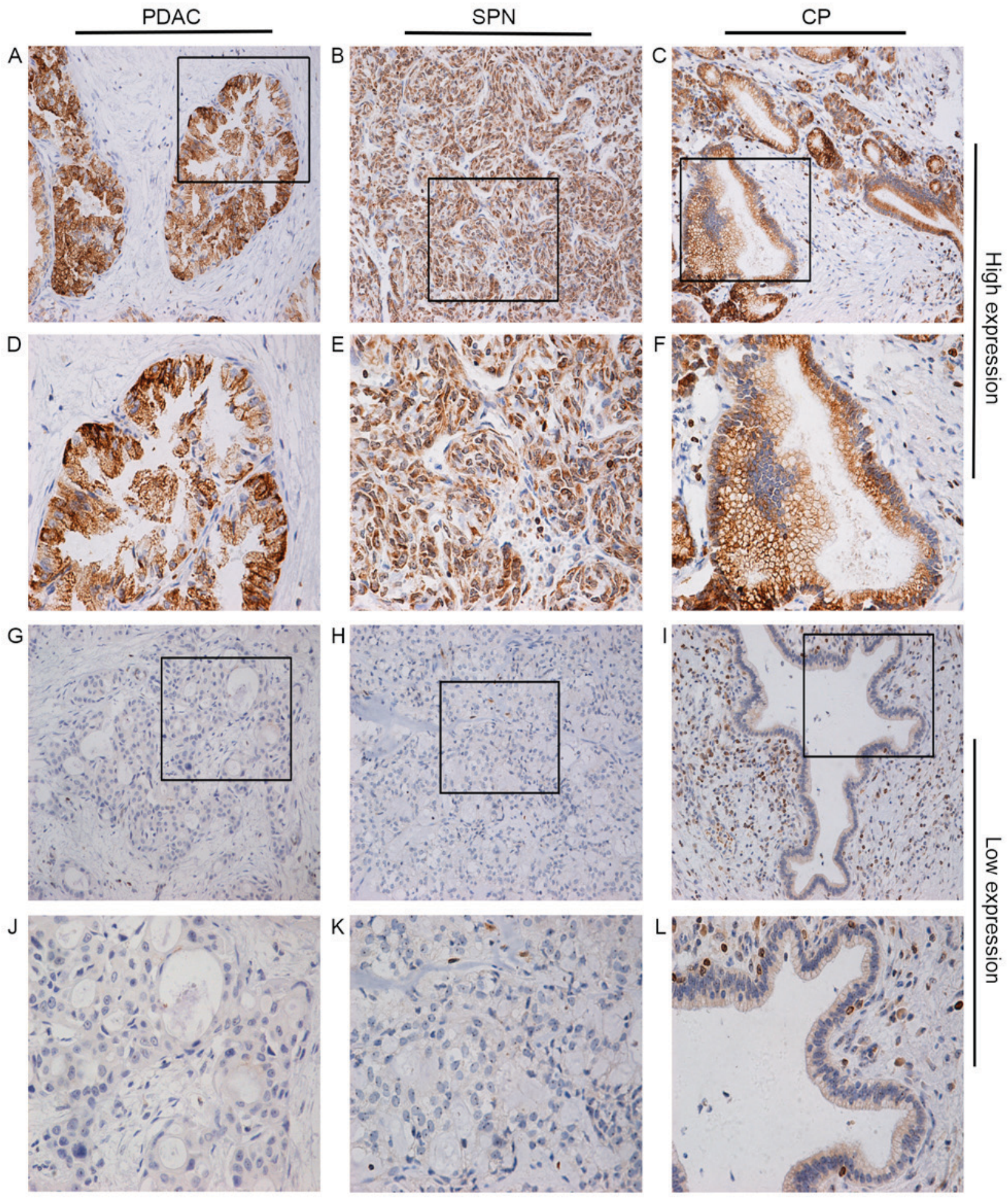

Figure 2. Immunohistochemical staining for high Bcl-2 expression in PDAC tissues at (A) magnification, $\mathrm{x} 200$ and (D) $\mathrm{x} 400$ in SPN tissues at (B) magnification, x200 and (E) x400 and in normal ductal epithelium in CP tissues at (C) magnification, x200 and (F) x400. Low Bcl-2 expression in PDAC tissues at (G) magnification, x200 and (J) x400 in SPN tissues at (H) magnification, x200 and (K) x400 and in normal ductal epithelium in CP tissues at (I) magnification, x200 and (L) x400. Lymphocytes in the pancreatic stroma were used as the positive controls (arrow). PDAC, pancreatic ductal adenocarcinoma; SPN, solid-pseudopapillary neoplasm; CP, chronic pancreatitis; Bcl-2, B-cell lymphoma-2.

and stress stages (31). Autophagy may initiate or inhibit apoptosis depending on the cellular context and stimulus, and the inhibition of autophagy may increase the sensitivity of cells to apoptotic signals (6). The present study focused on analyzing the correlation between Beclin 1 and $\mathrm{Bcl}-2$ expression in pancreatic tissues.
In previous studies, Beclin 1 downregulation was detected in glioblastoma, hepatocellular carcinoma, esophageal cancer, non-small cell lung cancer, bladder urothelial tumors and breast cancer (11-16), whereas Beclin 1 upregulation was identified in colorectal, ovarian and gastric cancer (17-19). The correlation between Beclin 1 expression and clinicopathological 
Table IV. Association between Beclin 1 and Bcl-2 expression.

Bcl-2 expression

\begin{tabular}{lcccr}
\cline { 2 - 3 } Beclin 1 expression & Low expression, $\mathrm{n}(\%)$ & High expression, $\mathrm{n}(\%)$ & $\mathrm{r}$ & P-value \\
\hline PDAC & & & -0.342 & $<0.001^{\mathrm{a}}$ \\
Low expression & $20(17.1)$ & $23(19.7)$ & & $0.016^{\mathrm{a}}$ \\
High expression & $59(50.4)$ & $15(12.8)$ & 0.365 & 0.692 \\
SPN & $16(37.2)$ & $1(2.3)$ & & 0.073 \\
Low expression & $16(37.2)$ & $10(23.3)$ & & \\
High expression & $5(15.6)$ & $13(40.6)$ & & \\
CP & $3(9.4)$ & $11(34.4)$ & & \\
Low expression & High expression & & & \\
\hline
\end{tabular}

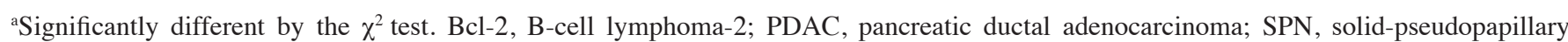
neoplasm; CP, chronic pancreatitis.

characteristics differs among different cancer tissues. Decreased expression of Beclin 1 is correlated with poor differentiation or advanced TNM stage, inducing early tumor relapse and causing low OS in glioblastoma (11), hepatocellular carcinoma (12), non-small cell lung cancer (14), breast cancer (16), ovarian cancer (17) and gastric carcinoma (19). Han et al (18) performed a meta-analysis, including six studies, to evaluate the prognostic significance of Beclin-1 expression in colorectal cancer, and revealed that Beclin 1 overexpression is associated with tumor metastasis and a poor prognosis in affected patients. Therefore, the effects of Beclin 1 expression levels differ among malignant tissues.

In the present study, high Beclin 1 expression was observed in $74(63.2 \%)$ PDAC cases, while 43 (36,8\%) PDAC cases exhibited low expression. Compared with the normal ductal epithelia in CP tissues, patients with PDAC demonstrated high Beclin 1 expression, and the difference was more apparent in poorly differentiated tissues and patients with advanced TNM stage. In the analysis of the correlations between Beclin 1 expression and clinicopathological characteristics, high Beclin 1 expression was associated with poor histological differentiation and distant metastasis. The univariate analysis of survival indicated that, despite a longer median DFS and OS in patients with low Beclin 1 expression compared with that in those patients with high expression, the difference was not statistically significant. In the multivariate Cox analysis, although low Beclin 1 expression was associated with improved OS $(\mathrm{P}<0.05)$, it was not an independent prognostic factor for PDAC. The significant prognostic factors based on PDAC itself were the differentiation status, local advancement and distal metastasis. Taken together, these results suggest that Beclin 1 expression is upregulated in PDAC tissues, and increased Beclin 1 levels serve a significant role in PDAC progression. High Beclin 1 expression affects the survival of patients with PDAC by affecting tumor differentiation, local advancement and distal metastasis; however, it was not an independent indicator of prognosis in patients with PDAC in the present study.

To the best of our knowledge, there is only one previous study analyzing Beclin 1 expression in patients with PDAC. In that study, Kim et al (36) evaluated Beclin 1 expression levels in 63 PDAC cases, with positive expression in 14 (22.2\%) cases and negative expression in $49(77.8 \%)$ cases. The results of correlation and survival analyses were different from those of the present study, and the immunohistochemical pattern was also different. The opposite outcomes may be attributed to differences in the methods used. In the present study, the Power Vision two-step method was chosen to perform the immunohistochemical staining, whereas Kim et al (36) chose the streptavidin-peroxidase three-step method in their study. In our opinion, the streptavidin-peroxidase three-step method is not suited to pancreatic tissue.

Bcl-2 protein is considered a carcinogenic protein, as it contributes to apoptosis inhibition; its tumorigenic potential has been demonstrated in animal models (37) and is supported by its overexpression in a variety of tumors and in lymphomas, in which Bcl-2 acts as an oncogene $(38,39)$. However, in certain solid tumors, Bcl-2 paradoxically appears to exert a tumor suppressor effect, and its expression is associated with favorable prognostic features. Callagy et al (40) performed a meta-analysis, including 17 studies and 5,892 breast cancer cases, to determine whether $\mathrm{Bcl}-2$ is an independent prognostic marker in breast cancer. The meta-analysis clearly supported the prognostic role of Bcl-2 expression in breast cancer, as assessed by immunohistochemistry, and demonstrated that it is associated with DFS and OS. The mechanisms by which Bcl-2 exerts its protective effects remain unclear.

In the present study, it was demonstrated that Bcl-2 expression was lower in PDAC tissues compared with the normal ductal epithelium in $\mathrm{CP}$ tissues, and that it was associated with poor differentiation, positive distant metastasis, advanced TNM stage and a poor prognosis. The outcomes revealed that $\mathrm{Bcl}-2$ is downregulated in PDAC tissues and that $\mathrm{Bcl}-2$ downregulation promotes PDAC progression, suggesting that $\mathrm{Bcl}-2$ is an independent prognostic indicator in PDAC. Consistent with the results of the present study, previous studies demonstrated decreased Bcl-2 expression in PDAC cancerous foci, and low Bcl-2 expression was associated with poor differentiation and high TNM stage cases $(26,41,42)$. 


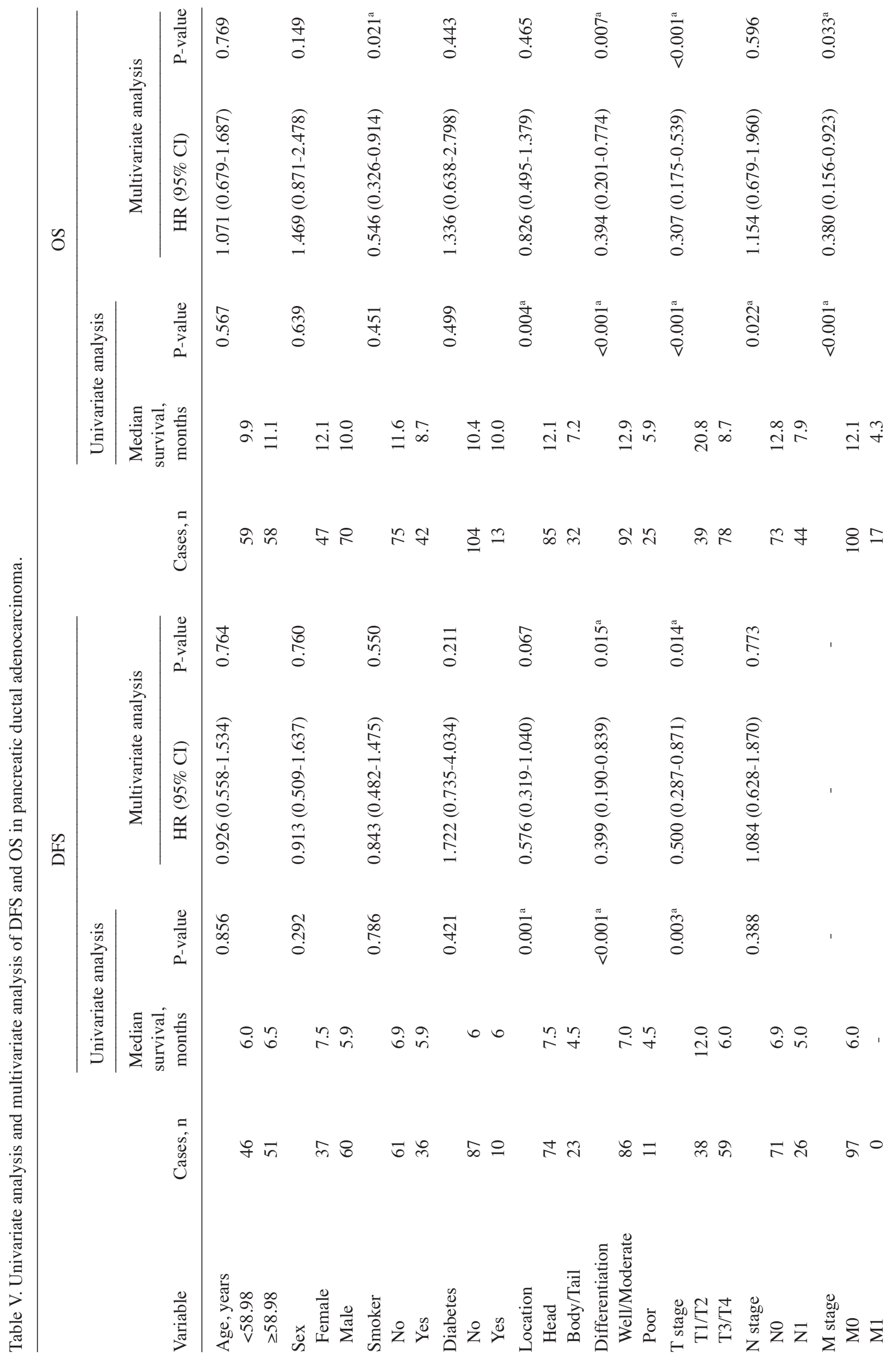




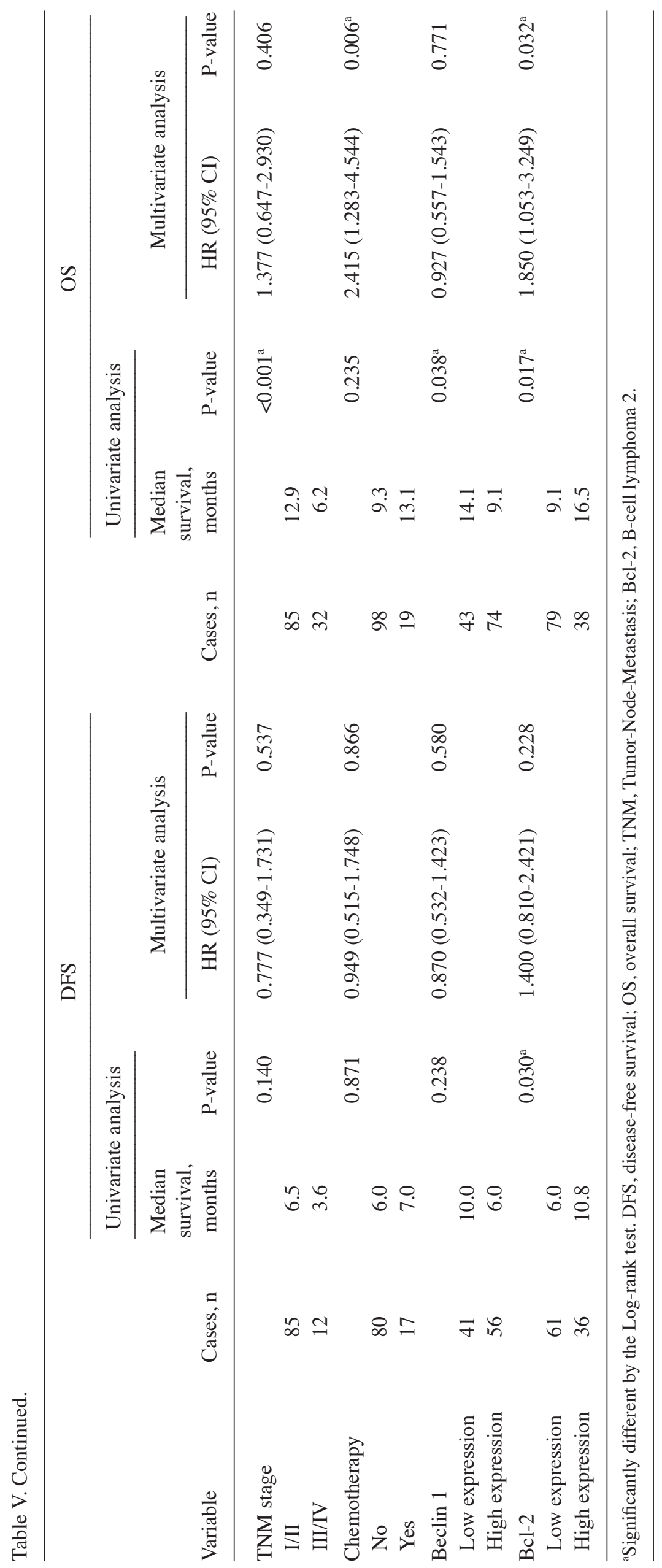




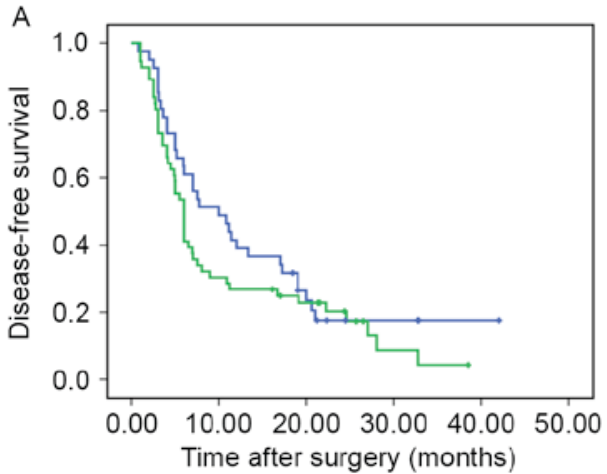

Beclin 1

expression

$\rightarrow$ Low expression

$\rightarrow$ High expression

+ Low expressioncensored

+ High expressioncensored

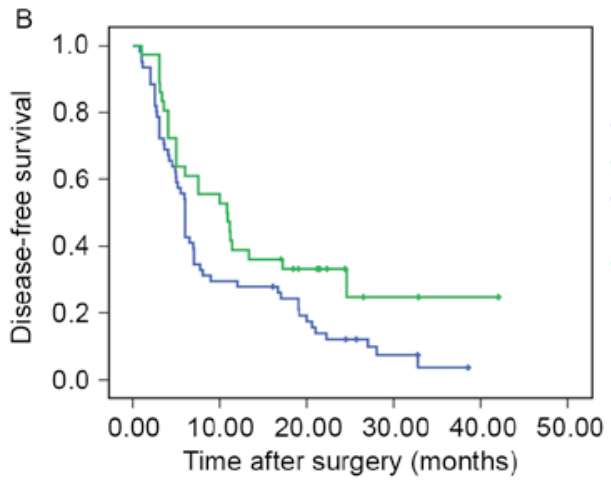

C

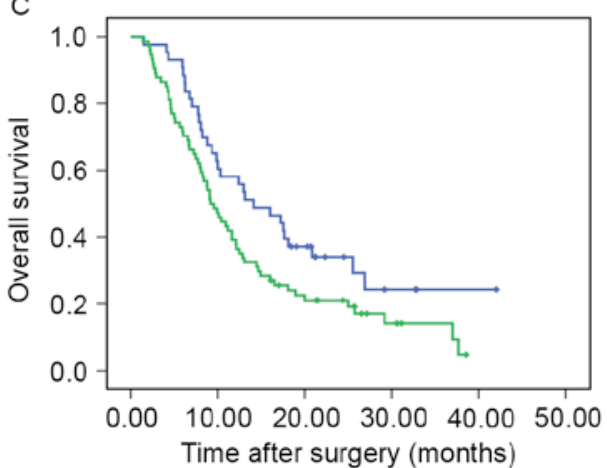

Beclin 1

expression

$\neg$ Low expression

$\rightarrow$ High exprssion

+ Low expressioncensored

+ High expressioncensored

D

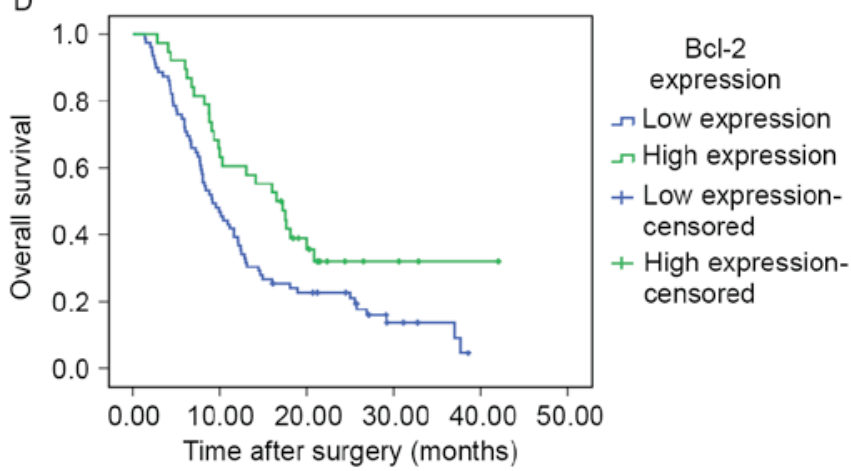

Figure 3. (A and B) Disease-free survival and (C and D) overall survival were analyzed by Kaplan-Meier analysis according to Beclin 1 and $\mathrm{Bcl}-2$ expression status. Bcl-2, B-cell lymphoma-2.

However, the prognostic significance of $\mathrm{Bcl}-2$ expression in patients with PDAC remains controversial, which may be attributed to population differences.

Knowlton et al (43) analyzed cell cycle progression in breast cancer cells and demonstrated a decreased $\mathrm{S}$ phase fraction and an increased $\mathrm{G}_{1} / \mathrm{G}_{0}$ fraction in Bcl-2(-) cells, suggesting that $\mathrm{Bcl}-2$ prolongs the cell cycle. Additionally,
Bcl-2 also enhanced the $G_{0}$ fraction and delayed $G_{0}$ to $S$ transition (44). Ke et al (45) revealed that Bcl-2 upregulation serves a critical role in the regulation of cell adhesion and migration via the formation of $\mathrm{Bcl}-2$ and gelsolin complexes, leading to the inhibition of cell diffusion, given the established correlation of cell motility with cancer metastasis. Despite the antiapoptotic effects favoring tumor survival, these results may explain why the expression of Bcl-2 in certain tumor cell types reduces the potential for metastasis and improves patient prognosis.

Another notable reason for the high relapse and low 5-year OS of PDAC is the poor sensitivity to chemotherapy, radiotherapy or immunotherapy. Therefore, a number of patients with PDAC refuse adjuvant therapy subsequent to surgery. As an important adjuvant therapy following tumor resection, chemotherapy serves an essential role in preventing tumor relapse and prolonging OS. Chemotherapy is the adjuvant therapy method considered to be potentially effective in PDAC (2). The modulation of cell apoptosis is one of the mechanisms of chemotherapy. A meta-analysis performed by Yang et al (46) revealed that Bcl-2 expression is a predictive factor for chemotherapy sensitivity, and negative Bcl-2 expression is associated with a good chemotherapy response in patients with breast cancer. Therefore, the modulation of Bcl-2 expression may potentially benefit additional clinical treatment for PDAC.

In the present study, Beclin 1 and Bcl-2 levels were inversely correlated in PDAC tissues. The inverse correlation between Beclin 1 and Bcl-2 expression has been demonstrated in previous studies $(16,27,28,47)$. Under normal conditions, Bcl-2 inhibits Beclin 1, whereas under conditions of stress, Beclin 1 dissociates from $\mathrm{Bcl}-2$, allowing the activation of Vps34 and the subsequent stimulation of autophagy (48). Bcl-2 inhibits autophagy when bound to Beclin 1 and downregulates Beclin 1, which is associated with the outcomes of patients in the present study (48). Reduced Bcl-2 expression leads to decreased interaction with Beclin 1, resulting in increased Beclin 1 levels and the stimulation of autophagy, primarily in patients with PDAC with poor prognostic factors.

SPN was first described by Frantz in 1959 (4), and defined by the World Health Organization as a 'solid pseudopapillary neoplasm', a low grade malignant neoplasm of the exocrine pancreas in 2010 (49). SPNs primarily affect young women in their $20 \mathrm{sec}$ and $30 \mathrm{sec}$, and generally form a well-demarcated mass with a mean diameter of $5-10 \mathrm{~cm}$. Despite their large size, the majority of these tumors behave indolently; complete surgical resection of SPNs may lead to a favorable prognosis, with a 5-year survival rate $>95 \%$ (50).

The present study detected Beclin 1 and Bcl-2 expression in SPN tissues, and detected 26 (60.5\%) cases with high Beclin 1 expression and 11 (25.6\%) cases with high Bcl-2 expression. High Beclin 1 expression was significantly correlated with the presence of nuclear pleomorphism. This result confirmed that increased Beclin 1 expression leads to poor tumor differentiation. Unlike PDAC, a direct correlation was detected between the levels of Beclin 1 and Bcl-2 expression in SPN cases. Additionally, the expression levels of Beclin 1 and Bcl-2 in normal ductal epithelium of $\mathrm{CP}$ tissues were not correlated. The differences in expression patterns indicated the tissue specificity of Beclin 1 and Bcl-2, suggesting that autophagy 
and apoptosis exhibit separate regulatory mechanisms in SPN. None of the patients exhibited tumor relapse, and all patients were alive by the date of last follow-up.

The present study has several limitations. Firstly, normalized chemotherapy for PDAC is generally performed based on the guidelines for pancreatic cancer treatment; however, few patients undergo chemotherapy due to the poor sensitivity of PDAC to adjuvant therapy and the ineffectiveness of primary chemotherapy strategies for PDAC. Therefore, the present study was unable to collect a large sample size of PDAC cases to analyze the association between the sensitivity to chemotherapy and Beclin 1 and Bcl-2 expression. Secondly, due to the unknown pathogenesis of SPNs, the present study was unable to detect changes in Beclin 1 and Bcl-2 expression in comparison with those in normal pancreatic tissues. Finally, due to the short follow-up time, none of the patients with SPN exhibited tumor relapse and all patients were alive by the date of last follow-up. Future studies with a larger sample size are necessary to overcome these limitations.

To conclude, the results of the present study suggest that Beclin 1 upregulation and Bcl-2 downregulation in PDAC promotes cancer progression, and that their expression is inversely correlated. High expression of $\mathrm{Bcl}-2$ is a favorable prognostic indicator in PDAC. Unlike the expression pattern in PDAC, Beclin 1 and Bcl-2 are positively correlated in SPN. High Beclin 1 expression may lead to poor progression of neoplasms.

\section{Acknowledgements}

The authors would like to thank the Science and Technology Department of Liaoning Province for supporting the present study (grant no. 2013225021).

\section{References}

1. Xiao AY, Tan ML, Wu LM, Asrani VM, Windsor JA, Yadav D and Petrov MS: Global incidence and mortality of pancreatic diseases: A systematic review, meta-analysis and meta-regression of population-based cohort studies. Lancet Gastroenterol Hepatol 1: 45-55, 2016.

2. Parker SL, Tong T, Bolden S and Wingo PA: Cancer statistics, 1997. CA Cancer J Clin 47: 5-27, 1997.

3. Singh D, Upadhyay G, Srivastava RK and Shankar S: Recent advances in pancreatic cancer: Biology, treatment and prevention. Biochim Biophys Acta 1856: 13-27, 2015.

4. Frantz VK: Atlas of tumor pathology, Section VII, Fascicles 27 and 28. Tumors of the Pancreas. Washington, D.C.: Armed forces institute of pathology. Brit J Surg 47: 334-334, 1959.

5. Levine B and Klionsky DJ: Development by self-digestion: Molecular mechanisms and biological functions of autophagy. Dev Cell 6: 463-477, 2004.

6. Liang XH, Jackson S, Seaman M, Brown K, Kempkes B Hibshoosh H and Levine B: Induction of autophagy and inhibition of tumorigenesis by beclin 1. Nature 402: 672-676, 1999.

7. Wang CW and Klionsky DJ: The molecular mechanism of autophagy. Mol Med 9: 65-76, 2003.

8. Shintani T and Klionsky DJ: Autophagy in health and disease: A double-edged sword. Science 306: 990-995, 2004.

9. Qu X, Yu J, Bhagat G, Furuya N, Hibshoosh H, Troxel A, Rosen J, Eskelinen EL, Mizushima N, Ohsumi Y, et al: Promotion of tumorigenesis by heterozygous disruption of the beclin 1 autophagy gene. J Clin Invest 112: 1809-1820, 2003.

10. Yue Z, Jin S, Yang C, Levine AJ and Heintz N: Beclin 1, an autophagy gene essential for early embryonic development, is a haploinsufficient tumor suppressor. Proc Natl Acad Sci USA 100: 15077-15082, 2003
11. Miracco C, Cosci E, Oliveri G, Luzi P, Pacenti L, Monciatti I, Mannucci S, De Nisi MC, Toscano M, Malagnino V, et al: Protein and mRNA expression of autophagy gene Beclin 1 in human brain tumours. Int J Oncol 30: 429-436, 2007.

12. Qiu DM, Wang GL, Chen L, Xu YY, He S, Cao XL, Qin J, Zhou JM, Zhang YX and E Q: The expression of beclin-1, an autophagic gene, in hepatocellular carcinoma associated with clinical pathological and prognostic significance. BMC Cancer 14: 327, 2014.

13. Chen Y, Lu Y, Lu C and Zhang L: Beclin-1 expression is a predictor of clinical outcome in patients with esophageal squamous cell carcinoma and correlated to hypoxia-inducible factor (HIF)-1alpha expression. Pathol Oncol Res 15: 487-493, 2009.

14. Zhou W, Yue C, Deng J, Hu R, Xu J, Feng L, Lan Q, Zhang W, $\mathrm{Ji} \mathrm{D}, \mathrm{Wu} \mathrm{J}$, et al: Autophagic protein beclin 1 serves as an independent positive prognostic biomarker for non-small cell lung cancer. PLoS One 8: e80338, 2013.

15. Baspinar S, Bircan S, Yavuz G and Kapucuoglu N: Beclin 1 and bcl-2 expressions in bladder urothelial tumors and their association with clinicopathological parameters. Pathol Res Pract 209: 418-423, 2013.

16. Dong M, Wan XB, Yuan ZY, Wei L, Fan XJ, Wang TT, Lv YC, $\mathrm{Li} \mathrm{X}$, Chen $\mathrm{ZH}$, Chen J, et al: Low expression of beclin 1 and elevated expression of HIF-1 $\alpha$ refine distant metastasis risk and predict poor prognosis of ER-positive, HER2-negative breast cancer. Med Oncol 30: 355, 2013.

17. Cai M, Hu Z, Liu J, Gao J, Liu C, Liu D, Tan M, Zhang D and Lin B: Beclin 1 expression in ovarian tissues and its effects on ovarian cancer prognosis. Int J Mol Sci 15: 5292-5303, 2014.

18. Han Y, Xue XF, Shen HG, Guo XB, Wang X, Yuan B, Guo XP, Kuang YT, Zhi QM and Zhao H: Prognostic significance of beclin-1 expression in colorectal cancer: A meta-analysis. Asian Pac J Cancer Prev 15: 4583-4587, 2014.

19. Chen YB, Hou JH, Feng XY, Chen S, Zhou ZW, Zhang XS and Cai MY: Decreased expression of beclin 1 correlates with a metastatic phenotypic feature and adverse prognosis of gastric carcinomas. J Surg Oncol 105: 542-547, 2012.

20. Korsmeyer SJ: Bcl-2 initiates a new category of oncogenes: Regulators of cell death. Blood 80: 879-886, 1992.

21. Seto M, Jaeger U, Hockett RD, Graninger W, Bennett S, Goldman P and Korsmeyer SJ: Alternative promoters and exons, somatic mutation and deregulation of the Bcl-2-Ig fusion gene in lymphoma. EMBO J 7: 123-131, 1988.

22. Reed JC, Miyashita T, Krajewski S, Takayama S, Aime-Sempe C, Kitada S, Sato T, Wang HG, Harigai M, Hanada M, et al: Bcl-2 family proteins and the regulation of programmed cell death in leukemia and lymphoma. Cancer Treat Res 84: 31-72, 1996.

23. Naccarato AG, Viacava P, Vignati S, Fanelli G, Bonadio AG, Montruccoli G and Bevilacqua G: Bio-morphological events in the development of the human female mammary gland from fetal age to puberty. Virchows Arch 436: 431-438, 2000.

24. Reed JC, Miyashita T, Takayama S, Wang HG, Sato T, Krajewski S, Aimé-Sempé C, Bodrug S, Kitada S and Hanada M: BCL-2 family proteins: Regulators of cell death involved in the pathogenesis of cancer and resistance to therapy. J Cell Biochem 60: 23-32, 1996.

25. Teraki Y and Shiohara T: Apoptosis and the skin. Eur J Dermatol 9: 413-425, 1999.

26. Tomaszewska R, Karcz D and Stachura J: An immunohistochemical study of the expression of bcl-2 and p53 oncoproteins in pancreatic intraepithelial neoplasia and pancreatic cancer. Int J Pancreatol 26: 163-171, 1999.

27. Won KY, Kim GY, Kim YW, Song JY and Lim SJ: Clinicopathologic correlation of beclin-1 and bcl-2 expression in human breast cancer. Hum Pathol 41: 107-112, 2010.

28. Baspinar S, Bircan S, Orhan H, Kapucuoglu N and Bozkurt KK: The relation of beclin 1 and bcl-2 expressions in high grade prostatic intraepithelial neoplasia and prostate adenocarcinoma: A tissue microarray study. Pathol Res Pract 210: 412-418, 2014.

29. Liang XH, Kleeman LK, Jiang HH, Gordon G, Goldman JE, Berry G, Herman B and Levine B: Protection against fatal sindbis virus encephalitis by beclin, a novel Bcl-2-interacting protein. J Virol 72: 8586-8596, 1998.

30. Decuypere JP, Parys JB and Bultynck G: Regulation of the autophagic bcl-2/beclin 1 interaction. Cells 1: 284-312, 2012.

31. Zhou F, Yang Y and Xing D: Bcl-2 and Bcl-xL play important roles in the crosstalk between autophagy and apoptosis. FEBS J 278: 403-413, 2011. 
32. Cao SS, Su AP, Du XJ, Li A, Hu WM, Zhang ZD, Tian BL, $\mathrm{Lu} \mathrm{HM}, \mathrm{Ke}$ NW and He ZP: The expressions and correlation of bcl-2 and beclin-1 in pancreatic cancer. Sichuan Da Xue Xue Bao Yi Xue Ban 43: 156-160, 2012 (In Chinese).

33. Chun YS, Pawlik TM and Vauthey JN: 8th Edition of the AJCC cancer staging manual: Pancreas and hepatobiliary cancers. Ann Surg Oncol, 2017 (Epub ahead of print).

34. Song S, Wang B, Zhang X, Hao L, Hu X, Li Z and Sun S: Long-term diabetes mellitus is associated with an increased risk of pancreatic cancer: A meta-analysis. PloS one 10: e0134321, 2015.

35. Asiyanbola B, Gleisner A, Herman JM, Choti MA, Wolfgang CL Swartz M, Edil BH, Schulick RD, Cameron JL and Pawlik TM: Determining pattern of recurrence following pancreaticoduodenectomy and adjuvant 5-flurouracil-based chemoradiation therapy: Effect of number of metastatic lymph nodes and lymph node ratio. J Gastrointest Surg 13: 752-759, 2009.

36. Kim HS, Lee SH, Do SI, Lim SJ, Park YK and Kim YW: Clinicopathologic correlation of beclin-1 expression in pancreatic ductal adenocarcinoma. Pathol Res Pract 207: 247-252, 2011

37. McDonnell TJ and Korsmeyer SJ: Progression from lymphoid hyperplasia to high-grade malignant lymphoma in mice transgenic for the $\mathrm{t}(14 ; 18)$. Nature 349: 254-256, 1991.

38. McDonnell TJ, Troncoso P, Brisbay SM, Logothetis C, Chung LW, Hsieh JT, Tu SM and Campbell ML: Expression of the protooncogene bcl-2 in the prostate and its association with emergence of androgen-independent prostate cancer. Cancer Res 52: 6940-6944, 1992.

39. Pietenpol JA, Papadopoulos N, Markowitz S, Willson JK Kinzler KW and Vogelstein B: Paradoxical inhibition of solid tumor cell growth by bcl2. Cancer Res 54: 3714-3717, 1994.

40. Callagy GM, Webber MJ, Pharoah PD and Caldas C: Meta-analysis confirms BCL2 is an independent prognostic marker in breast cancer. BMC Cancer 8: 153, 2008.
41. Campani D, Esposito I, Boggi U, Cecchetti D, Menicagli M, De Negri F, Colizzi L, Del Chiaro M, Mosca F, Fornaciari G and Bevilacqua G: Bcl-2 expression in pancreas development and pancreatic cancer progression. J Pathol 194: 444-450, 2001

42. Casneuf VF, Fonteyne P, Van Damme N, Demetter P, Pauwels P, de Hemptinne B, De Vos M, Van de Wiele C and Peeters M: Expression of SGLT1, Bcl-2 and p53 in primary pancreatic cancer related to survival. Cancer Invest 26: 852-859, 2008

43. Knowlton K, Mancini M, Creason S, Morales C, Hockenbery D and Anderson BO: Bcl-2 slows in vitro breast cancer growth despite its antiapoptotic effect. J Surg Res 76: 22-26, 1998.

44. Zinkel S, Gross A and Yang E: BCL2 family in DNA damage and cell cycle control. Cell Death Differ 13: 1351-1359, 2006.

45. Ke H, Parron VI, Reece J, Zhang JY, Akiyama SK and French JE: BCL2 inhibits cell adhesion, spreading, and motility by enhancing actin polymerization. Cell Res 20: 458-469, 2010.

46. Yang D, Chen MB, Wang LQ, Yang L, Liu CY and Lu PH: Bcl-2 expression predicts sensitivity to chemotherapy in breast cancer: A systematic review and meta-analysis. J Exp Clin Cancer Res 32: 105, 2013.

47. Jiang LC, Huang SY, Zhang DS, Zhang SH, Li WG, Zheng PH and Chen ZW: Expression of beclin 1 in primary salivary adenoid cystic carcinoma and its relation to $\mathrm{Bcl}-2$ and $\mathrm{p} 53$ and prognosis. Braz J Med Biol Res 47: 252-258, 2014

48. Pattingre S, Tassa A, Qu X, Garuti R, Liang XH, Mizushima N, Packer M, Schneider MD and Levine B: Bcl-2 antiapoptotic proteins inhibit beclin 1-dependent autophagy. Cell 122: 927-939, 2005.

49. Klöppel G, Hruban R, Klimstra D, et al: Solid-pseudopapillary Tumor of Pancreas. In: Bosman FT, Carneiro F, Hruban RH, Theise ND, editors: 327-333, 2010.

50. Potrc S, Kavalar R, Horvat M and Gadzijev EM: Urgent Whipple resection for solid pseudopapillary tumor of the pancreas. J Hepatobiliary Pancreat Surg 10: 386-389, 2003. 